\title{
Cultivation Countermeasures of Vocational College Students' Professional Ethics Education from the Perspective of Craftsman Spirit
}

\author{
Hong-Da ZHANG \\ China university of mining and technology ( Beijing ), china \\ zhdyx2011@163.com
}

Keywords: craftsman spirit; Professional ethics education; Nurturing; Higher vocational colleges

\begin{abstract}
The spirit of the craftsmanship, first for the enterprise, is now the spiritual quality that all walks of life cannot lack. As the main channel of conveying technical talents for the society, vocational colleges are indispensable to cultivate the spirit of craftsmanship for students' professional ethics education. Based on the analysis of craftsmen's spirit and vocational moral education in higher vocational colleges, this paper discusses the significance and countermeasures of implementing Professional ethics education in higher vocational colleges based on the educational goal of cultivating craftsmen's spirit, so as to provide a feasible reference for improving the Professional ethics education system and methods of students in higher vocational colleges and cultivating and cultivating students' simple craftsmen's spirit.
\end{abstract}

\section{Introduction}

As one of the contents of ideological and political education, professional ethics education is of great significance to improve students' own professional ethics level, and craftsmanship spirit also plays an important role in promoting students to develop good professional ethics habits. Moral education is the current direction of higher education and the provisions of the inner soul. At the same time, the cultivation of craftsmen's spirit is also a new issue facing the higher vocational and technical education, the cultivation of craftsmen's spirit as the starting point of school professional ethics education to implement professional ethics education, for higher vocational education, is essential, is also necessary.

\section{The Relationship Between the Spirit of the Craftsman and the Professional Ethics Education} in Higher Vocational Colleges

\section{The Connotation of the Spirit of the Craftsman}

The spirit of the craftsman refers to the craftsman's pursuit of perfection in his products and the pursuit of a more perfect and extreme work attitude and spiritual concept. The real craftsmen like to keep carving their products and try their best product to make their products perfect. However, there are many phenomena of frivolity and impracticality in today's society, many people only pursue immediate short-term interests, and ignore the quality of the products and the long-term sustainable development benefits. The goal of the spirit of the craftsman is to create the best in the industry and put the customer-oriented service spirit at the top of their work. It is this spiritual existence that can restrain social impetuousness and achieve the ultimate in goods and services. In today's China, the rapid development of economy and people's pursuit of quality are in contradiction with the current situation of social floating, impetuous and superficial. It makes people more and more eager to the spirit of the craftsman and advocate it.

\section{The Connotation of Vocational Moral Education in Higher Vocational Colleges}

Professional ethics is the sum of moral standards, behavioral norms and psychological consciousness that are closely linked to this activity in the process of people's professional activities, which is a moral responsibility and obligation to their work and society. [1] A person is both a social and professional person. The quality of morality is a reflection of the professional's responsibility 
and obligation in professional activities. In today's society, the basic reason for the desalination of the spirit of craftsman and even in some areas is the lack of professional moral spirit.

The foundation of higher vocational colleges lies in high moral values establishment and people cultivation. Students from higher vocational colleges have their presence in all social jobs. Whether they have the quality of honesty, cooperation, professionalism and dedication in their work is an outstanding embodiment of the content of professional ethics education. For students in higher vocational colleges, to conduct professional ethics education is of great significance to enhancing their vocational awareness and improving their overall quality. For higher vocational education, strengthening professional ethics education is not only a historical law for the growth of talents, but also a realistic requirement for enhancing graduates' employment competitiveness.

\section{The Relationship between Spirit of Craftsmanship and Professional Ethics Education in Higher Vocational Colleges}

Professional ethics education and craftsmanship spirit cultivation complement, interact and cooperate with each other, jointly guiding students to form a correct and scientific world view, view of life and values. The spirit of craftsmanship is precisely the embodiment of emphasis on the cultivation of professional ethics education for students in higher vocational colleges in our country.

Good professional ethics is the quality required by the social and economic development, and it is naturally the core and main point of school professional ethics education. Vocational moral educators in higher vocational colleges should regard the cultivation of students' spirit of craftsmanship as an entry point and improve vocational ethics education system in higher vocational colleges, and they should organize and implement professional ethics education taking spirit of craftsmanship as the core.[2] Regarding spirit of craftsmanship as an important content of professional ethics education will inevitably contribute to the transformation from "Made in China" to "Created in China".

\section{The Importance of Promoting the Spirit of Craftsmanship to Improve Vocational Moral Education of Students in Higher Vocational Colleges}

\section{The Role of Vocational Awareness in Vocational College Students}

Professional awareness is a consciousness as a professional person, and it is a comprehensive reflection of psychological components, such as cognition, evaluation and integrity of professional labor. High quality compound talents should have the following abilities in today's knowledge economy era, that is, moral quality, innovation quality, skill quality and physical quality. Professional ethics education can help students establish a sense of hard work and dedication, guide students to work hard, study hard to improve their own quality, in the future work to better produce high-quality products.

Promoting the spirit of artisans can make students in higher vocational colleges develop a sense of ownership in the professions they are engaged in in the future, and bring forth new ideas, dedication consciousness and cooperation consciousness in the process of imperceptibly. Higher vocational colleges in the process of cultivating students to enable students to deeply understand the artisan spirit, will be provided to the students' awareness of the artisan spirit level, the occupation moral internalization in the minds of students, students in the future occupation career development, naturally abide by their occupation behavior, keep in mind the industry occupation moral.

\section{The Role of Professional Ethics Training in Vocational College Students}

Professional ethics education is an important link in the moral education of Higher Vocational Colleges in China, and it has not been paid enough attention at present. The education goal of higher vocational colleges is to cultivate skilled and talented people with good moral character and professional ability. Having high professional ethics quality is an important feature of higher vocational talents. Professional ethics education has always been an important part of moral education. If we do well in professional ethics education, we can combine theory with practice, and 
promote the enrichment and effective utilization of teaching resources, which is conducive to the ultimate goal of moral education

Promoting the spirit of craftsmanship in the process of professional ethics education can make students in higher vocational colleges understand that working is not only a tool to make a living for their families, but also to treat their professional activities strictly with the spirit of craftsmanship, to pursue perfection and ultimate quality, and to complete the task with high-quality, can achieve their own value. At the same time, the establishment of the professional reverence, dedication to work, the attitude towards product responsible, and constantly absorbing the most advanced technologies, in order to achieve excellence, to maintain and improve the industry's honor, and to create new labor achievements.

\section{The Role of Professional Attitude Cultivation for Higher Vocational College Students.}

Professional attitude is the concept of selection process such as self-expectation, career market demand and career development direction. No matter what kind of work you do, as long as you can make achievements and make contributions to society, you will get social affirmation. Only by clearly recognizing this point, students in higher vocational colleges can establish the correct professional attitude and form good professional habits.

The younger generation is the future of our country, shouldering the arduous task of building the country and realizing "Chinese dream", the great rejuvenation of Chinese nation. The cultivation of professional attitudes of students in higher vocational colleges should adhere to the concept of the spirit of craftsmanship, so that students can correct their professional attitudes at the beginning of their career choices and set up correct values; so that they can form professional dedication and spiritual attitude in the course of their careers; Students maintain a progressive professional attitude while developing their careers. In this way, regardless of whether the students are before the career, during the career, or after the career, they can remember the spirit of craftsmanship all the time and take a positive professional attitude towards future career and life.

\section{The Cultivation of Higher Vocational Students' Professional Moral Education in the sight of craftsmanship's spirit}

\section{Pay Attention to the Role and Position of Craftsmanship's Spirit}

Since the 1990s, along with the rapid economic development, higher vocational colleges have been in a state of rapid expansion. However, the expansion of the enrollment scale did not make the students of higher vocational colleges truly become technical talents, focusing on quantity and slighting quality appeared in higher vocational colleges. This concept of talent cultivation has hindered the sustainable development of higher vocational colleges, and also brought uncertain factors to the economic development of modern society. The publish of The outline of the National Medium and Long-Term Education Reform and Development Plan (2010-2020), points out the development direction for the cultivation of talents in higher vocational colleges, meaning that "professional education must focus on cultivating students' professional ethics, professional skills, and employment and entrepreneurship.” In the 2020s, a modern vocational education system will be established to meet the requirements of changes in the mode of economic development and adjustment of industrial structure, and meet the requirements of the economic society for highly qualified workers and skilled personnel[3].Higher vocational colleges should change their own concept of running schools in accordance with the spirit of the document, in which we should treat the number expansion and quality improvement of students equally and pay attention to the role and status of craftsmanship to form a talent training model with the aim of cultivating craftsmanship.

\section{Accelerate Education and Teaching Reform, Sound Scientific Evaluation System}

Higher vocational colleges generally have such problems, many students performed very well in all aspects during school, however, after entering the actual work of the company, often the results of the employee work evaluation are not satisfactory. The main reason for this phenomenon is that the 
school evaluation system is unscientific, and businesses and schools have different ways to evaluate student professional ethics and actual work efficiency, which results in the evaluation results not accurately reflecting the students' moral standards. The inaccuracy of the evaluation results is due to the inconsistent evaluation standards of businesses and schools. So schools should combine firstly the individual characteristics of students, and based on the characteristics of the enterprise career evaluation system, establish a comprehensive career evaluation system for school-enterprise interaction. The scientific comprehensive career evaluation system has a positive effect on the education and teaching reform in higher vocational colleges, and it also has a certain role in promoting the professional ethics education level in higher vocational colleges. Higher vocational colleges need to establish and improve a scientific evaluation system for professional ethics education, schools and businesses achieve good interaction, ensuring that students meet the professional ethics of the company.

\section{Exploring the Cooperation between School and Enterprise to Improve the Effectiveness of the Mode of Running a School}

School enterprise cooperation mode is a cooperative mode established by schools and enterprises. It is a win-win mode that pays attention to resources and information sharing between schools and enterprises, and is also one of the important ways to cultivate vocational morality of vocational college students. Compared with the cultivation of other professional qualities, the cultivation of the craftsman spirit needs rely on more abundant knowledge and more advanced technology. Carrying out the cooperation between school and enterprise, it is necessary for students to develop the craftsman's spirit in the process of employment. To this end, students should be able to master the knowledge, technology and skills of a complete industrial chain. At the same time, school enterprise cooperation can enable students to develop practical learning habits, grasp practical learning methods and skills, and enhance the ability of finding and solving problems. To carry out school-enterprise cooperation, recruiting corporate experts to teach in schools or as part-time school teachers ,to communicate with students, by communicating with students can make students learn a variety of professional skills that across the entire industry chain. After the knowledge level has been accumulated to a certain extent, it is used as the basis for its own professional quality. At the same time, school enterprise cooperation can enable students to grasp practical learning methods and skills, enhance the ability of finding and solving problems, and develop practical learning habits that practice and research, summary and improvement are carried out synchronously.

\section{Strengthening Practice Education is an Important Way to Cultivate the Spirit of the Craftsman}

Practice is the object activity of people's understanding of the world and the transformation of the world. Through practice, professional ethics can be internalized as the individual quality and moral accomplishment of the practitioner. Theoretically speaking, some kind of professional ethics is often vague. When we cultivate students' professional ethics, we must put theoretical knowledge in the real situation, so that students can understand better what is professional ethics. In the process of occupation moral education, the practical education of "pass on personal teachings to pupils and body granted" is helpful for students to cultivate the artisan spirit and stimulate students to form a good occupation emotion. Mutual imparting and comprehension in their heart between teachers and students is the inner psychological transfer easier to implement technology learning objectives. At the same time, the practice education of "set an example by personally taking part" can let the students experience the spirit of the craftsman. To experience and develop a better professional spirit, students need to practice technical skills in continuous practice. Only in the concrete practice education, the students will feel the same, and eventually transform the craftsman spirit into a kind of internal professional ethics. 


\section{Reference}

[1]Zhu Xiangnan. The Implication and Realization Path of Vocational Moral Education in Higher Vocational Colleges [J]. education and profession, 2016 (8).

[2]Fostering Vocational College Students' Professional Qualities Against the Background of Advocating Craftsmanship[J]. education and occupation, 2016 (8).

[3]Program of National Medium and Long Term Education Reform and Development (2010-2020 years) [M]. Beijing: People's publishing house, 2010. 